\title{
Continuous sky view factor maps from high resolution urban digital elevation models
}

\author{
F. Lindberg*, C. S. B. Grimmond \\ Environmental Monitoring and Modelling Group, Department of Geography, King's College London, London WC2R 2LS, UK
}

\begin{abstract}
This paper presents a new method to calculate sky view factors (SVFs) from high resolution urban digital elevation models using a shadow casting algorithm. By utilizing weighted annuli to derive SVF from hemispherical images, the distance light source positions can be predefined and uniformly spread over the whole hemisphere, whereas another method applies a random set of light source positions with a cosine-weighted distribution of sun altitude angles. The 2 methods have similar results based on a large number of SVF images. However, when comparing variations at pixel level between an image generated using the new method presented in this paper with the image from the random method, anisotropic patterns occur. The absolute mean difference between the 2 methods is 0.002 ranging up to 0.040 . The maximum difference can be as much as 0.122 . Since SVF is a geometrically derived parameter, the anisotropic errors created by the random method must be considered as significant.
\end{abstract}

KEY WORDS: Urban climate · Urban geometry · Urban surface parameters · Geographical Information Systems $\cdot$ Sky view factor $\cdot$ London

\section{INTRODUCTION}

The sky view factor (SVF), an extensively used parameter, is a measure of the degree to which the sky is obscured by the surroundings for a given point (Grimmond et al. 2001). Watson \& Johnson (1987) express SVF as the ratio of radiation received by a planar surface to that received from the entire hemispheric radiating environment. There are a wide range of methods to determine this parameter, including the analysis of fish-eye photos (Steyn 1980). For explanatory illustrations of SVF and fish-eye photos, see Fig. 2 in Gál et al. (2009) and Fig. 2 in Grimmond et al. (2001), respectively. SVF has been used in a variety of studies including energy exchange (e.g. Nunez et al. 2000, Jonsson et al. 2006), spatial variations of urban air and surface temperature patterns (e.g. Yamashita et al. 1986, Eliasson 1996, Upmanis \& Chen 1999) and outdoor thermal comfort (Matzarakis et al. 2007, Lindberg et al. 2008), as well as in the modelling of the urban climate (e.g. Oke 1981, Unger 2006). SVF is also used in other re- search areas such as forest meteorology (Grimmond et al. 2000) and urban planning (Ratti \& Richens 2004).

During the last decade, methods to derive continuous images of SVF from high resolution urban digital elevation models (DEMs) have been developed (Ratti \& Richens 1999). The Ratti \& Richens (1999) SVF method has been evaluated and found to be very accurate (Lindberg 2005), and it is also considerably faster than other vector-based methods available (e.g. Gál et al. 2009). It has been used in a number of atmospheric and architectural studies (e.g. Ratti et al. 2006, Lindberg 2007, Martilli 2009). This raster-based approach makes it easier to investigate the spatial variations and characteristics of SVF, as well as to derive the parameter for urban climate modelling.

The objective of the present study is to present a new raster-based method to calculate SVFs from high resolution urban DEMs and to compare it against simple geometries whose SVF is exactly known, as well with the already existing raster-based method originally developed by Ratti \& Richens (1999). 


\section{METHODS}

The SVF can be derived using a shadow casting algorithm with the altitude and azimuth of a distant light source (the sun) used as input together with the raster DEM (Fig. 1A). The approach to generate a shadow is to compute shadow volumes as a new DEM. This is done by sequentially moving a raster DEM at the azimuth angle of the sun, while reducing the height for each iteration based on sun elevation angle

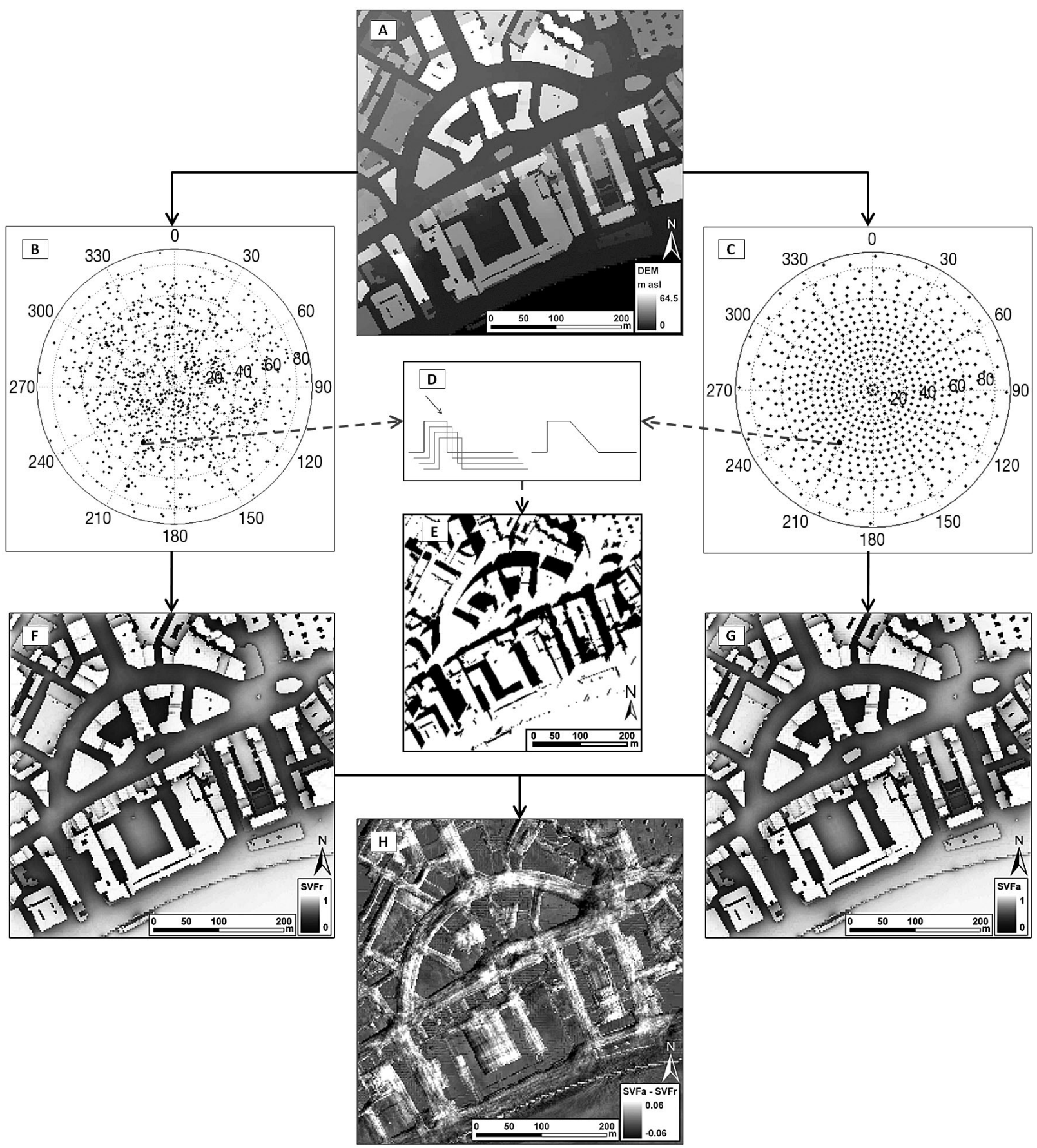

Fig. 1. Process used to derive continuous images of sky view factor (SVF). (A) A digital elevation model (DEM) of central London. Polar plots of sun positions on the hemisphere for $(B)$ the random method $\left(\mathrm{SVF}_{\mathrm{r}}\right)$ and $(\mathrm{C})$ the proposed new method $\left(\mathrm{SVF} \mathrm{F}_{\mathrm{a}}\right)$. (D) $\mathrm{A}$ schematic showing the repeated translation of a DEM with a simultaneous reduction of its 'height' (left), which allows the detection of the shadow volume (right). (E) Example of a single Boolean shadow image (azimuth $=210^{\circ}$, altitude $=41^{\circ}$ ). SVF images generated by the $(\mathrm{F}) \mathrm{SVF}_{\mathrm{r}}$ and $(\mathrm{G}) \mathrm{SVF}_{\mathrm{a}}$ methods. $(\mathrm{H})$ Example of anisotropy patterns in SVF between a single image generated by the $\mathrm{SVF}_{\mathrm{r}}$ and $\mathrm{SVF}_{\mathrm{a}}$ methods $\left(\mathrm{SVF}_{\mathrm{a}}-\mathrm{SVF}_{\mathrm{r}}\right)$ 
(Fig. 1D, left). For each iteration, a part of the shadow volume is derived and, by taking the maximum of this volume for each iteration, the whole shadow volume is built up (Fig. 1D, right). The algorithm continues until the moving DEM has an elevation below the original DEM or is outside the area of interest. To produce an actual map of shadows, the original DEM is subtracted from the shadow volume image and a Boolean image is produced where pixels with a negative or zero value are those exposed to sunlight and given a new value of 1 , and positive values are in shade and given a new value of 0 (Fig. 1E). The computational software MAT$\mathrm{LAB}^{\circledR}$ (MathWorks ${ }^{\mathrm{TM}}$ ) was used to generate the SVF images.

\subsection{Generating continuous images of SVFs using a random number approach}

To calculate the SVF for all pixels in a DEM using the method proposed by Ratti \& Richens (1999), 1000 shadow maps are generated, where solar altitude and azimuth are randomly chosen for each separate shadow map (Fig. 1B,F). Since SVF is a measure of radiative exchanges between surfaces, the solar altitude angles are multiplied by a cosine factor. By applying random angles of altitudes and azimuths (i.e. sun positions) instead of predefined angles, the emergence of patterns of interference is prevented. For a detailed description of the shadow casting algorithm and SVFimage generation, see Ratti (2001) or Ratti \& Richens (2004).

\subsection{A new method to generate continuous images of SVFs}

In the new method, instead of using random Sun positions, the concept of annulus weighting as proposed by Steyn (1980), which he developed to compute SVF from hemispherical photographs, is used:

$$
\mathrm{SVF}_{\mathrm{a}}=\sum_{i=1}^{\mathrm{n}} S \frac{2}{2 \pi} \sin \left(\frac{\pi}{180}\right) \sin \left(\frac{\pi\left(2 \alpha_{i}-1\right.}{2 n}\right) \frac{360}{\theta_{i}}
$$

The annulus-weighted SVF $\left(\mathrm{SVF}_{\mathrm{a}}\right)$ image is created by computing the sum of weighted shadow maps, where $S$ is the Boolean image of shadow patterns, $\mathrm{n}$ is the total number of shadow maps generated, $\alpha_{i}$ is the altitude angle in degrees and $\theta_{i}$ is the number of azimuth angles used at the $i$ th annulus level. Using this method, the sun positions can be predefined and uniformly spread over the whole hemisphere with a minor weighting towards $25<\alpha<65$ where the variation of hemispheric blocking from buildings usually occurs in the urban environment (Fig. 1c). This also means that the number of shadow castings can be reduced while still obtaining an accurate result. Here, the new number of sun positions is reduced to 653 . When reducing the number of shadow images in the SVF calculation there is a risk of creating detectable patterns in the final SVF image. For example, this kind of pattern of interference could be created if a high number of sun positions were aligned at the same azimuth angle. To prevent this, the azimuth angles are offset at the different levels of altitude angle (Fig. 1C).

\section{COMPARISON OF METHODS}

Initially, both raster-based methods were compared with the analytical method given by Oke (1987) for 2 ideal cases: (1) a circular basin $\left(\mathrm{H}: \mathrm{W}=0.5 ; \mathrm{SVF}_{\text {basin }}\right)$ and (2) an infinitely long east-west canyon (H:W $=1$; $\left.\mathrm{SVF}_{\text {canyon }}\right)$, where $\mathrm{H}: \mathrm{W}$ is the height to width ratio. The SVF calculations are done for a centre point in both cases. The equations for the analytical computations are:

$$
\mathrm{SVF}_{\text {canyon }}=\cos \beta \text { and } \mathrm{SVF}_{\text {basin }}=\cos ^{2} \beta
$$

where $\beta$ is the elevation angle from the centre to the wall. For both methods, similar results are obtained when compared to the analytical method (Table 1). The annuli method $\left(\mathrm{SVF}_{\mathrm{a}}\right.$, Eq. 1) gives a 0.012 lower SVF-value in the ideal case of the circular basin (0.400) and a 0.013 higher SVF-value for the infinite canyon (0.447). Using the random method $\left(\mathrm{SVF}_{\mathrm{r}}\right)$, a mean absolute error (MAE) of 0.009 is obtained for the circular basin and 0.012 for the infinite canyon. The $\mathrm{SVF}_{\mathrm{r}}$ method produces a different value for each generated SVF image, and because of the random solar altitude and azimuth angles, it is necessary to calculate the MAE. For the $\mathrm{SVF}_{\mathrm{a}}$ method with the fixed solar altitude and azimuth angles, the results are identical each time. Here, for the $\mathrm{SVF}_{\mathrm{r}} \mathrm{MAE}$ analysis, 10 separate SVF images were analysed.

Table 1. Statistics of the sky view factor (SVF) comparison between the annuli $\left(\mathrm{SVF}_{\mathrm{a}}\right)$ and random $\left(\mathrm{SVF}_{\mathrm{r}}\right)$ methods. $\mathrm{H}: \mathrm{W}$ : height to width ratio; MAE: mean absolute error

\begin{tabular}{|lcccccc|}
\hline & $\mathrm{H}: \mathrm{W}$ & $\mathrm{SVF}$ & $\mathrm{SVF}_{\mathrm{r}}(\mathrm{MAE})$ & $\mathrm{SVF}_{\mathrm{a}}$ \\
\hline $\mathrm{SVF}_{\text {basin }}$ & 0.5 & 0.400 & 0.009 & -0.012 \\
$\mathrm{SVF}_{\text {canyon }}$ & 1 & & 0.447 & 0.012 & 0.013 \\
& & & & \multicolumn{4}{c}{$\mathrm{SVF}_{\mathrm{a}}-\mathrm{SVF}_{\mathrm{r}}$} & \\
\cline { 5 - 7 } & $\mathrm{H}: \mathrm{W}$ & $\mathrm{SVF}$ & $\mathrm{Mean}$ & $\mathrm{SD}$ & $\mathrm{Max}$ & $\mathrm{Min}$ \\
\hline $\mathrm{SVF}_{\text {blocks }}$ & 1 & 0.557 & -0.002 & 0.013 & 0.036 & -0.040 \\
\hline
\end{tabular}




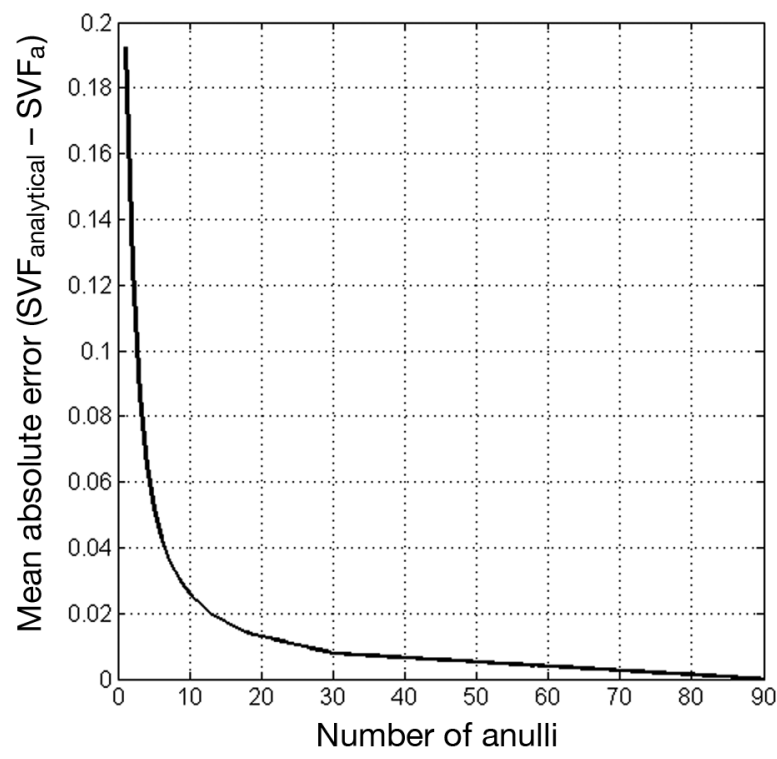

Fig. 2. Mean absolute errors of $\mathrm{SVF}_{\text {basin }}$ between the analytical $\left(\mathrm{SVF}_{\text {analytical }}\right)$ and annuli methods $\left(\mathrm{SVF}_{\mathrm{a}}\right)$ based on the number of annuli used

The error given by the $\mathrm{SVF}_{\mathrm{a}}$ method varies with the number and distribution of sun positions used in the calculation (Fig. 1C) as well as the raster resolution of the DEM. Increasing the number of points increases the accuracy of the model, but as a consequence, the computation time increases. To find the appropriate number of annuli, a comparison was made between the analytical ( $\left.\mathrm{SVF}_{\text {analytical }}\right)$ and annuli approaches. Based on the results (Fig. 2), here the number of annuli was set to 20, as increasing the number beyond that does not result in a significant increase in accuracy, but does increase the computation time required. Fig. 2 allows the trade-off, which may be appropriate, or necessary for other applications to be considered.

From a pixel-to-pixel comparison between an SVF image generated by the $\mathrm{SVF}_{\mathrm{r}}$ and $\mathrm{SVF}_{\mathrm{a}}$ methods, large anisotropical patterns are obtained (e.g. darker areas close to east facing building walls in Fig. 1H). The reason for this is that the 1000 random sun positions are not evenly spread over the whole hemisphere in $\mathrm{SVF}_{\mathrm{r}}$ (Fig. 1B). There are probably 2 main factors causing this anisotropical pattern. First, 2 random elements are derived for each sun position, an azimuth and one altitude angle, and it appears that 1000 sun positions are not sufficient to create an even distribution. Second, random numbers used in computer programs are pseudo-random, which means they are a generated in a predictable fashion using a mathematical formula, which implies that the distribution of random numbers are not completely random (Chaitin 2001). This discrepancy between the 2 methods is almost impossible to detect by visual comparison (Fig. 1F, G). However, the difference can be seen when the images are compared in detail. Therefore, a more comprehensive comparison between the 2 raster-based methods was

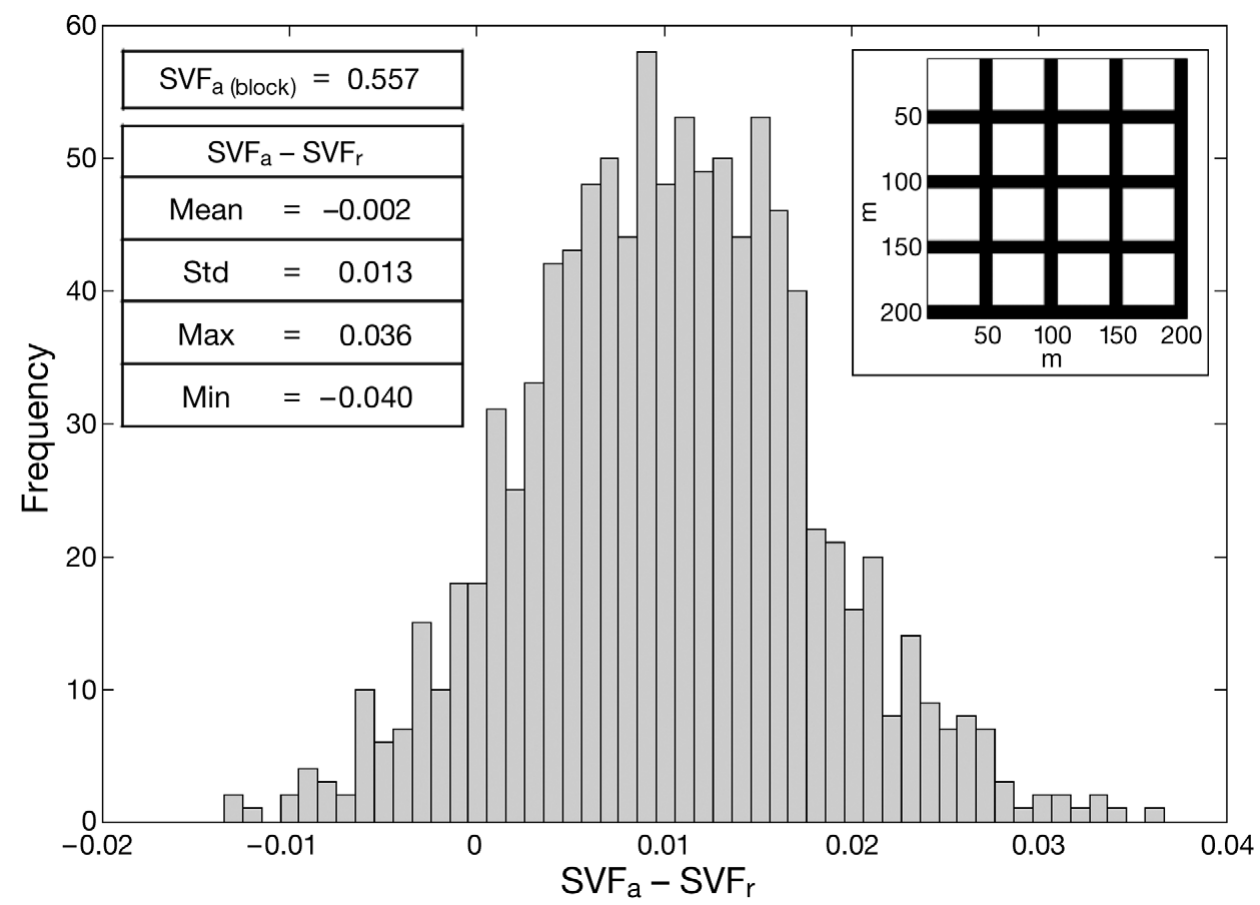

Fig. 3. Frequency distribution of differences in mean canyon floor sky view factor $\left(\mathrm{SVF}_{\mathrm{blocks}}\right)$ from 1000 generated images of $\mathrm{SVF}_{\mathrm{a}}-\mathrm{SVF}_{\mathrm{r}}$ (number of pixels compared for each image generated $=14400$ ). Inset: digital elevation model used for the comparison of the 2 methods. White areas are building blocks (height $=10 \mathrm{~m}$ ) and thick black lines are street canyons (height $=0 \mathrm{~m}$ ) 
A

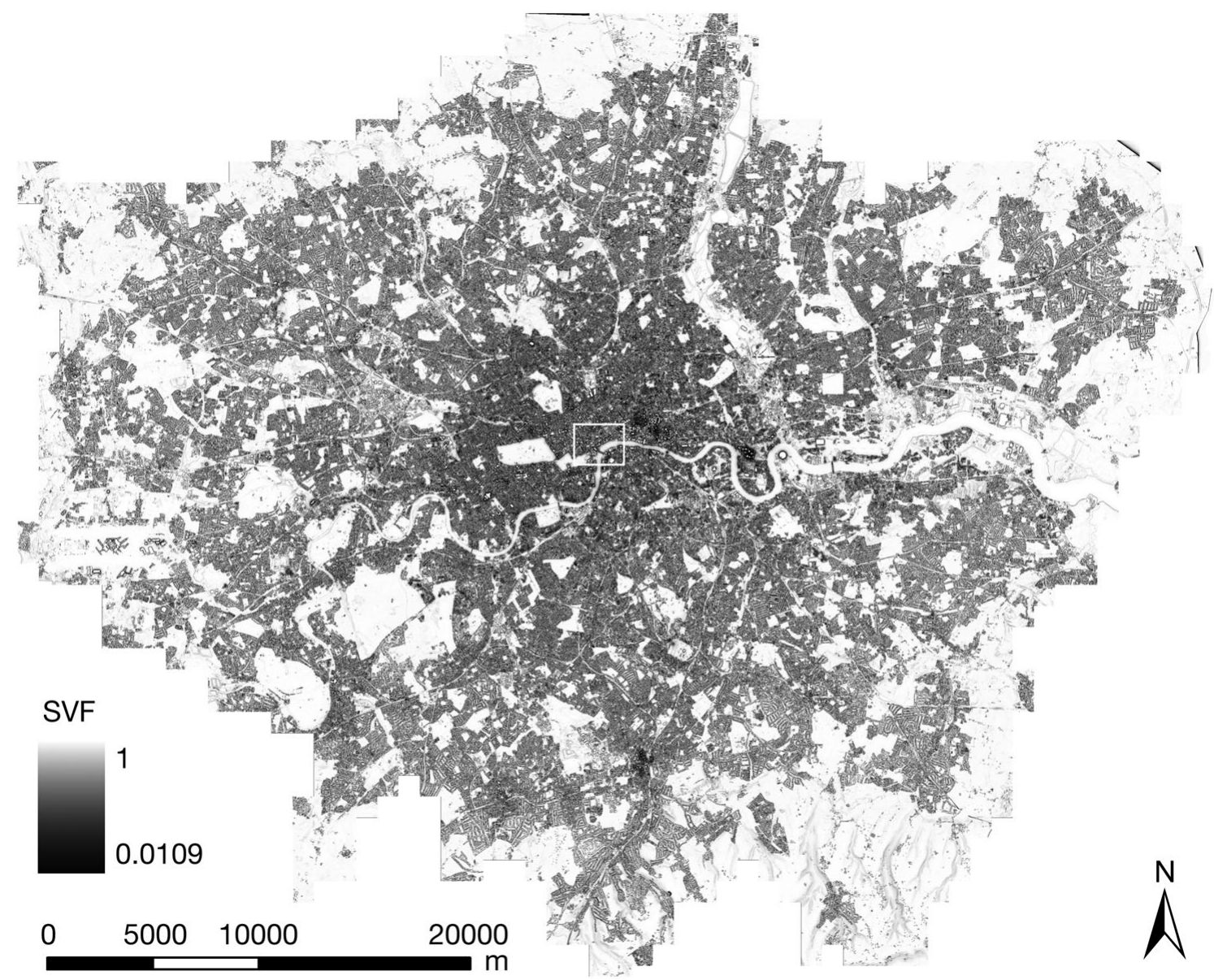

B

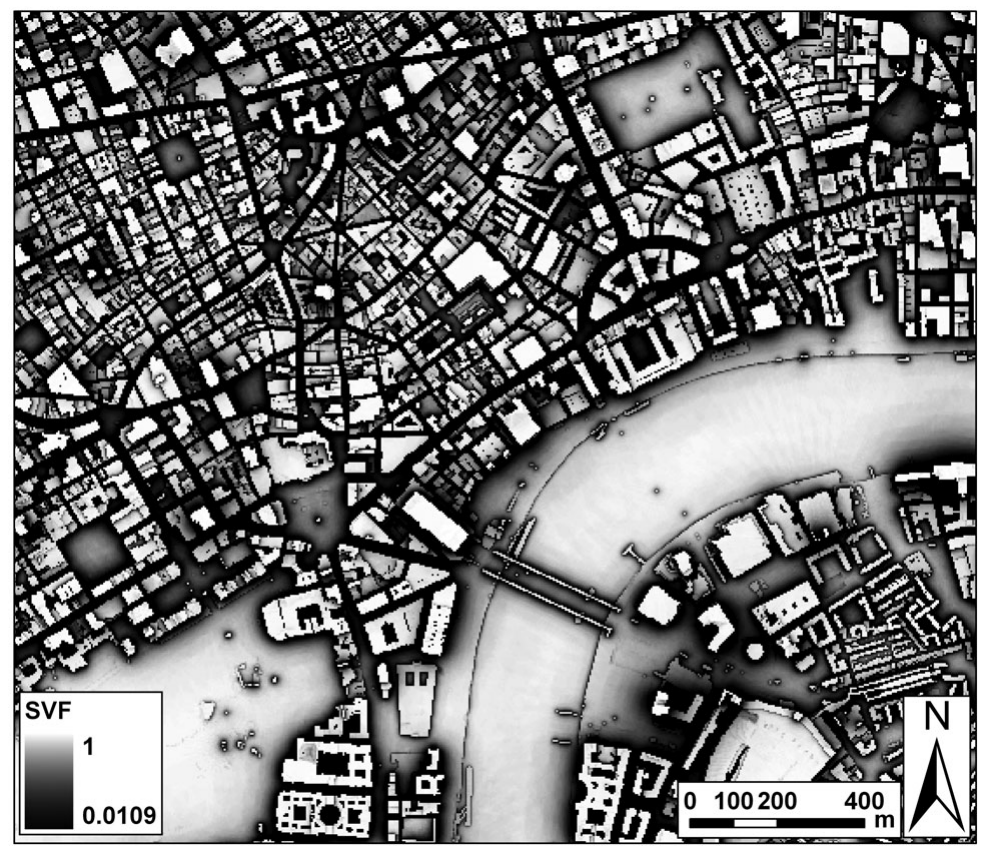

Fig. 4. (A) A continuous image of $\mathrm{SVF}_{\mathrm{a}}$ for Greater London, UK. Spatial resolution is $4 \mathrm{~m}$. White box in (A) indicates position of (B). (B) Enlargement on a central part of London 
made by generating SVF images using a simple DEM with street canyons of $\mathrm{H}: \mathrm{W}=1$ (Fig. 3, inset). One thousand images were generated for the $\mathrm{SVF}_{\mathrm{r}}$ method. Since the product of the $\mathrm{SVF}_{\mathrm{a}}$ method is the same for each generation, only 1 SVF image was generated and used for the pixel-to-pixel comparison. The 2 methods had very similar results $\left(\mathrm{SVF}_{\text {(blocks) }}\right.$, Table 1$)$. The $\mathrm{SVF}_{\mathrm{a}}$ image was 0.002 greater than the average from the $\mathrm{SVF}_{\mathrm{r}}$ images $($ mean $=0.557$ ). The distribution of mean differences from 1000 generated images of $\mathrm{SVF}_{\mathrm{a}}-\mathrm{SVF}_{\mathrm{r}}$ based on the DEM in Fig. 3 (inset) is presented in the same figure. As SVF values at roof level (white areas in Fig. 3 inset) were 1 for both methods, these pixels were excluded from the statistics analysis. Examining maximum discrepancies, the difference in maximum and mean values were 0.069 and 0.023 , respectively (data not shown), and the maximum range of error for a single image comparison between the 2 methods was as much as 0.122 (data not shown). Since SVF is a geometrically derived parameter, the anisotropic errors created by the $\mathrm{SVF}_{\mathrm{r}}$ method must be considered as significant.

The generation of $\mathrm{SVF}_{\mathrm{a}}$ requires slightly more computer time despite the smaller number of iterations (653 compared to 1000). The computation time for the $\mathrm{SVF}_{\mathrm{a}}$ and $\mathrm{SVF}_{\mathrm{r}}$ methods using the DEM in Fig. 3 on a regular PC (Intel ${ }^{\circledR}$ Core $^{\mathrm{TM}}$ Duo, $2.5 \mathrm{GHz}, 3 \mathrm{~GB}$ RAM) was 5.09 and $5.00 \mathrm{~s}$, respectively. This is because of the higher number of shadow castings from low altitude angles. Shadow maps generated from low altitude angles take longer than from high angles, as the objects (e.g. buildings) create longer shadows. Even though $\mathrm{SVF}_{\mathrm{a}}$ is slightly slower than the $\mathrm{SVF}_{\mathrm{r}}$ method, the increase in computation time is acceptable due to the improved accuracy and consistency in the $\mathrm{SVF}_{\mathrm{a}}$ method.

\section{APPLICATION EXAMPLE: GENERATING MAPS OF SVFs}

Using the method presented here $\left(\mathrm{SVF}_{\mathrm{a}}\right)$, the spatial variations of SVF over very large areas can be rapidly generated. As an example, an SVF image covering Greater London was produced (Fig. 4a). The mean SVF for the whole model domain is 0.927 . The input data consisted of a vector data set (Virtual London) comprising ground and building heights (Evans et al. 2006) which were converted into a raster DEM. The pixel resolution in Fig. 4 was $4 \mathrm{~m}$. The computation time of the SVF image using the $\mathrm{SVF}_{\mathrm{a}}$ method was approximately $72 \mathrm{~h}$ using a regular PC (Intel ${ }^{\circledR}$ Core $^{\text {TM }}$ Duo, $2.5 \mathrm{GHz}, 3 \mathrm{~GB}$ RAM) for the 163875000 data points. The computation time using the $\mathrm{SVF}_{\mathrm{r}}$ method and the vector method presented in Gál et al. (2009) would have been approximately 77 and 550 h, respectively.
Since the DEM only consists of ground and building topography, it is evident that vegetation is missing, which affects the shadow patterns and thus the SVF values. Including vegetation units in this type of model is challenging for various reasons. There is the complex 3-dimensional nature of leaves, plus the absence of leaves and branches in the trunk zone below the canopy. Casting shadows is therefore difficult in a raster-based model, which can be described as a 2.5D model (each pixel in a DEM includes only 1 height value). For the same reason, complex urban settings such as galleries and overhanging façades are not represented in this model, whereas models such as ENVImet (www.envi-met.com/) are able to deal with these complex geometries. An additional aspect of vegetation is that it is a semi-permeable medium that changes with time (seasons, turgidity). Nevertheless, ongoing work is currently taking place at King's College London to include trees in raster modelling such as the SVF model presented in this paper. In the generation of large-scale SVF maps such as Fig. 4a, it is possible to take large-scale topography into account, which could be important in cities located in valleys or mountainous regions. As shown in Fig. 4b, large variations of SVF are found within the urban environment. The large variations of SVF over short distances lead, for example, to increased loss of energy at night and an altered microclimate (Oke 1981).

\section{CONCLUSIONS}

An exact method to calculate SVFs from high resolution urban DEMs using a shadow casting algorithm was presented. By using the concept of annulus weighting to derive SVF from hemispherical images, predefined sun positions can be evenly spread over the whole hemisphere. Comparing a large number of $\mathrm{SVF}_{\mathrm{r}}$ images with a $\mathrm{SVF}_{\mathrm{a}}$ image shows similar results between the 2 methods. However, when comparing variations at pixel level between an image generated using $\mathrm{SVF}_{\mathrm{r}}$ with the image from $\mathrm{SVF}_{\mathrm{a}}$ anisotropical patterns occur. The mean difference $\left(\mathrm{SVF}_{\mathrm{a}}-\mathrm{SVF}_{\mathrm{r}}\right)$ is 0.002 ranging up to 0.040 and the maximum range of error can be as much as 0.122 under this simple geometry. Since SVF is a geometrically derived parameter, the anisotropic errors created by the $\mathrm{SVF}_{\mathrm{r}}$ method must to be considered as significant. The method presented cam be utilized in research and applications concerned with outdoor thermal comfort, urban climate modelling and climate planning.

Acknowledgements. This work was financially supported by the Swedish Research Council for Environment, Agricultural Sciences and Spatial Planning (FORMAS) and the European 
Community's Seventh Framework Programme FP/2007-2011 MEGAPOLI (212520) and BRIDGE (211345) projects. The method presented in this paper is available through a userfriendly interface linked to the SOLWEIG-model. The interface can be downloaded from the Göteborg Urban Climate Group website (www.gvc2.gu.se/ngeo/urban/Activities/solweig.htm).

\section{LITERATURE CITED}

Chaitin GJ (2001) Exploring randomness. Springer-Verlag, London

Eliasson I (1996) Urban nocturnal temperatures, street geometry and land use. Atmos Environ 30:379-392

Evans S, Hudson-Smith A, Batty M (2006) 3-D GIS: Virtual London and beyond. An exploration of the 3-D GIS experience involved in the creation of Virtual London. Cybergeo Eur J Geogr 359

Gál T, Lindberg F, Unger J (2009) Computing continuous sky view factor using 3D urban raster and vector databases: comparison and an application for urban climate. Theor Appl Climatol 95:111-123

Grimmond CSB, Robeson SM, Schoof JT (2000) Spatial variability of micro-climatic conditions within a mid-latitude deciduous forest. Clim Res 15:137-149

Grimmond CSB, Potter SK, Zutter HN, Souch C (2001) Rapid methods to estimate sky-view factors applied to urban areas. Int J Climatol 21:903-913

Jonsson P, Eliasson I, Holmer B, Grimmond CSB (2006) Longwave incoming radiation in the Tropics: results from field work in three African cities. Theor Appl Climatol 85: 185-201

Lindberg F (2005) Towards the use of local governmental 3-d data within urban climatology studies. Mapp Image Sci 2: $32-37$

Lindberg F (2007) Modelling the urban climate using a local governmental geo-database. Meteorol Appl 14:263-273

Lindberg F, Holmer B, Thorsson S, (2008) SOLWEIG 1.0. Modelling spatial variations of 3D radiant fluxes and mean

Editorial responsibility: Helmut Mayer, Freiburg, Germany radiant temperature in complex urban settings. Int J Biometeorol 52:697-713

Martilli A (2009) On the derivation of input parameters for urban canopy models from urban morphological datasets. Boundary-Layer Meteorol 130:301-306

- Matzarakis A, Rutz F, Mayer H (2007) Modelling radiation fluxes in simple and complex environments: application of the RayMan model. Int J Biometeorol 51:323-334

> Nunez M, Eliasson I, Lindgren J (2000) Spatial variation of incoming longwave radiation in Göteborg, Sweden. Theor Appl Climatol 67:181-192

> Oke TR (1981) Canyon geometry and the nocturnal urban heat island: comparison of scale model and field observations. J Climatol 1:237-254

Oke TR (1987) Boundary layer climates. Routledge, London

Ratti CF (2001) Urban analysis for environmental prediction. $\mathrm{PhD}$ dissertation, Darwin College, University of Cambridge

Ratti CF, Richens P (1999) Urban texture analysis with image processing techniques Proc CAADFutures99, Atlanta, GA

Ratti CF, Richens P (2004) Raster analysis of urban form. Environ Plann B 31:297-309

> Ratti CF, Di Sabatino S, Britter R (2006) Urban texture analysis with image processing techniques: winds and dispersion. Theor Appl Climatol 84:77-90

Steyn DG (1980) The calculation of view-factors from fisheyelens photographs. Atmos-ocean 18:254-258

Unger J (2006) Modelling of the annual mean maximum urban heat island using 2D and 3D surface parameters. Clim Res 30:215-226

Upmanis H, Chen DL (1999) Influence of geographical factors and meteorological variables on nocturnal urban-park temperature differences - a case study of summer 1995 in Göteborg, Sweden. Clim Res 13:125-139

Watson ID, Johnson GT (1987) Graphical estimation of skyview factors in urban environments. J Climatol 7:193-197

Yamashita S, Sekine K, Shoda M, Yamashita K, Hara Y (1986) on relationships between heat island and sky view factor in the cities of Tama River basin, Japan. Atmos Environ 20:681-686

Submitted: February 2, 2010; Accepted: May 19, 2010 Proofs received from author(s): July 8, 2010 